\title{
Transparency in Health Care: Disclosing Adverse Events to the Public
}

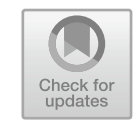

\author{
Siri Wiig, Karina Aase, Mathilde Bourrier and Olav Røise
}

\begin{abstract}
The topic of transparency has received increasing academic interest in recent years. Transparency can be interpreted as conducting affairs in the open, being subject to public scrutiny, or admitting to problems when they arise. This chapter analyses transparency in disclosing adverse events to the public in Norway. We use the widely publicized Daniel case to show the communication between the regulator and the public, discussing key elements of transparency in the healthcare setting, including the role of media. The Daniel case describes an accidental tonsillectomy characterized by cover-up, failure of the initial regulatory and hospital follow-up, coming to a head when media shone a spotlight on the case. The media coverage caused social amplification of the risk communication resulting in regulatory follow-up having to apply new forms of transparency strategies to rebuild trust in the public. By using the Daniel case as emblematic of Norwegian risk communication strategies in health care, improvements should be made along the lines of direct and adequate information exchange according to patient rights, and efforts to foster open and transparent regulatory and organizational cultures to ensure public trust.
\end{abstract}

Keywords Transparency · Adverse events · Risk amplification Health care

S. Wiig $(\square) \cdot$ K. Aase $\cdot$ O. Røise

SHARE - Center for Resilience in Healthcare, Faculty of Health Sciences,

University of Stavanger, Stavanger, Norway

e-mail: siri.wiig@uis.no

M. Bourrier

Department of Sociology and Institute of Sociological Research,

University of Geneva, Geneva, Switzerland

O. Røise

Division of Orthopaedic Surgery, Oslo University Hospital, Oslo, Norway

O. Røise

Institute of Clinical Medicine, University of Oslo, Oslo, Norway

(C) The Author(s) 2018 


\section{Introduction}

\section{Background}

It is commonly claimed that we live in an age of transparency (Hood and Dixon 2015) or in a 'transparency society' (Han 2015). The topic of transparency has therefore received increasing academic interest, resulting in theoretical and empirical propositions. Transparency can be interpreted as conducting affairs in the open, being subject to public scrutiny, or admitting to problems when they arise. Transparency may improve the communication of benefits and risks, and support the spread and sharing of knowledge. There is little doubt that transparency is fundamentally important from democratic and efficiency perspectives, although it may also have negative implications. More information and more communication do not necessarily lead to better decisions about risk, and the call for increased transparency may also increase costs and complicate decision-making processes (Han 2015; Hood and Dixon 2015). Some transparency strategies may involve dedicated web portals, publication of recommendations, introduction of public hearings, establishment of safety and quality committees and disclosure of the minutes of meetings and meeting agendas (Bouder et al. 2015).

In Norway's healthcare context, transparency trends are developing in line with greater international emphasis on holding healthcare providers accountable and relying more on performance indicators (e.g. Kurtzman and Jennings 2008; Tavare 2012). More specifically, more hospitals are making their adverse event rates public and posting hospital infection rates on their websites. Hospitals also disclose the number of patient complaints, their performance on national quality indicators, and waiting times (e.g. AHUS 2015; OUS 2015).

Promoting patient safety using a system perspective has shown promising results in improving health care and reducing adverse events. However, the use of error disclosure and the creation of transparent safety cultures have not been rigorously assessed or implemented (Francis 2015; Liang and Lovett 2013; Waring 2015). Healthcare scandals in several countries have shown that uncaring and ineffective practices can flourish if the organizational context goes wrong (Braithwaite et al. 2015; Francis 2013; Mannion and Davies 2015). There are still intimations of a culture of individual blame within health care, supported by professional cover-ups of adverse events (Johnstone and Kanitsaki 2006; Wiig and Lindøe 2009; Woodier 2015), and a fear of whistleblowing (Mannion and Davies 2015; Waring 2015). Healthcare professionals, managers and regulators alike have been accused, especially by the media, of avoiding transparent and open communication with patients and next of kin after adverse events (e.g. Aase and Rosness 2015; Francis 2013; Hannawa et al. 2016; Helsetilsynet 2015a, b; NOU 2015:11; Woodier 2015).

The nature of communication and regulation of risk has changed in Europe (Lofstedt et al. 2011; O'Connor 2016). Regulatory scandals have resulted in greater public distrust of regulators and policymakers and new models of regulation emerged with focus on public participation, transparency and increasingly powerful 
non-governmental organizations. The call for greater transparency developed to ensure more open decision-making processes, as regulators and policymakers were no longer trusted. The role of media as an independent 'watch dog' is crucial and implies that journalists may become advocates and take strong stances, and in many cases amplifying the risks associated with the topic that they are covering (Kasperson et al. 1988; Lofstedt et al. 2011).

The Norwegian Board of Health Supervision (NBHS) is the national regulatory body for health and care services. It is a public institution organized under the Ministry of Health and Care Services. At the regional level, 18 county governors oversee services within primary and specialized health care. In 2010, a new investigative group was established as part of the NBHS to improve regulatory follow-up after serious adverse events in Norwegian specialized healthcare services. To ensure transparency, the NBHS publishes anonymized versions of investigative reports, summary reports, and has recently increased its transparency approach by publishing a draft report. The 2015 draft report was based on an in-depth regulatory follow-up investigation of the death of a 3-year-old child after a routine tonsillectomy (the Daniel case) in 2009 (Helsetilsynet 2015a, b). The regulatory follow-up and the police investigation in the Daniel case were initially closed in 2010, but new information from the news media caused the regulatory case to be reopened in 2014 (Aftenposten, June, 20, 2014). At that time, the new investigation unit within the NBHS was operative and took on the task.

\section{Aim}

This chapter analyses transparency in disclosing adverse events to the public in Norway. We use the widely publicized Daniel case to show the communication between the regulator and the public, discussing key elements of transparency in the healthcare setting, including the role of media.

\section{Theoretical Approach}

This paper applies the Social Amplification of Risk Framework (SARF) (e.g. Kasperson et al. 1988; Pidgeon et al. 2003), as the theoretical foundation to understand the role of media in a high-profile case. It identifies how a new regulatory transparency approach has implications for the portrayal of events, interpretation of the event from different societal actors' perspectives and has unforeseen implications. In brief, the SARF is an integrative framework that depicts the dynamic social processes underlying risk perception and response. It is founded on the belief that hazards interact with psychological, social, institutional and cultural processes in ways that may increase or decrease the perception of risk and shape risk behaviour. The experience of risk is not just an experience of physical harm; it 
is also the result of a process by which individuals or groups learn to acquire or interpret hazards (Kasperson et al. 1988; Pidgeon et al. 2003).

Hazardous events hold a signal value, which individuals and social groups may perceive differently. These signals are subject to transformations as they are filtered through individual and social amplification stations (e.g. mass media, groups of scientists, governmental agencies, and politicians). Social amplification may have repercussions far beyond the initial impact of the event, bringing effects such as demands for regulatory constraints, litigation or loss of credibility and trust. These processes imply that diverse hazards are given more or less attention due to the diverse understanding of signals among individuals and groups, causing an amplification or attenuation of risks (Pidgeon et al. 2003).

\section{Methods}

We apply a retrospective case study strategy in the 'Daniel case' to understand the trajectory of the event and its implications for different stakeholders between 2009 and 2015 (Stake 1994). In this study, we conceive the case as the adverse event and the following activity among the stakeholders in the aftermath of Daniel's death. This paper is based on a qualitative content analysis (Pope et al. 2006) of publicly available data material on the Daniel case. The data material includes newspaper articles, news briefs from national media, and the preliminary draft version and the final investigation report published by the Norwegian Board of Health Supervision (NBHS). The main data sources are the draft version and the final version of the investigation report from the NBHS. The newspaper articles and news briefs have been used as a supplement to the investigative reports, adding narratives and voices related to the event, and also to provide insight into details, not covered by the mandate of the NBHS's investigative reports. All of the data material was downloaded from the Internet, and the study did not require ethical approval for collecting and analysing the data. The institution names, occupational positions, roles and responsibility were all present in the data material as it appeared in the published public documents. We have not disclosed any new information in this case. We analysed the material using a thematic approach where we read all of the material and then categorized the data according to the themes emerging from the data (Pope et al. 2006). We analysed the data to gain insight into (a) the chronological process between the regulator and the public, (b) the implications of a new transparency approach and (c) the influence of the media on the development and escalation of the case from the beginning of 2009 when Daniel died, to the end of 2015, after the NBHS published the results of the final investigation. 


\section{Findings}

In this section, we present the findings chronologically. We begin with a description of the adverse event, the internal follow-up, and the regulatory and police investigations in 2009. Then, we describe how media dug up new information in 2014, the reopening of the case, and the implications of the new transparency policy in 2015. Figure 1 gives the timeline of the Daniel case.

\section{The Daniel Case: What Happened?}

Daniel, aged 2 years and 11 months, was referred for chronic tonsillitis to the otorhinolaryngeal unit of Molde Hospital in north-western Norway. He had been having monthly throat infections, snoring, difficulties with speech and food intake and was accepted for surgery by the chief consultant. At admission for surgery January, 16, 2009, the patient was re-examined by a resident who classified the large tonsils as grade 3-4 according to Friedman's four-grade scale and confirmed the indication for surgery. No documented information was given to the parents on the particular risks associated with this surgery on such a young child. The patient underwent an uncomplicated adenotonsillectomy and was discharged from the hospital the next morning.

On day three after surgery, the patient was readmitted for bleeding. At admission, the bleed had stopped and the patient was prophylactically treated with antibleeding medication and surveyed fasting at the recovery unit. The patient was treated with penicillin due to elevated CRP. Neither blood screening nor reservation
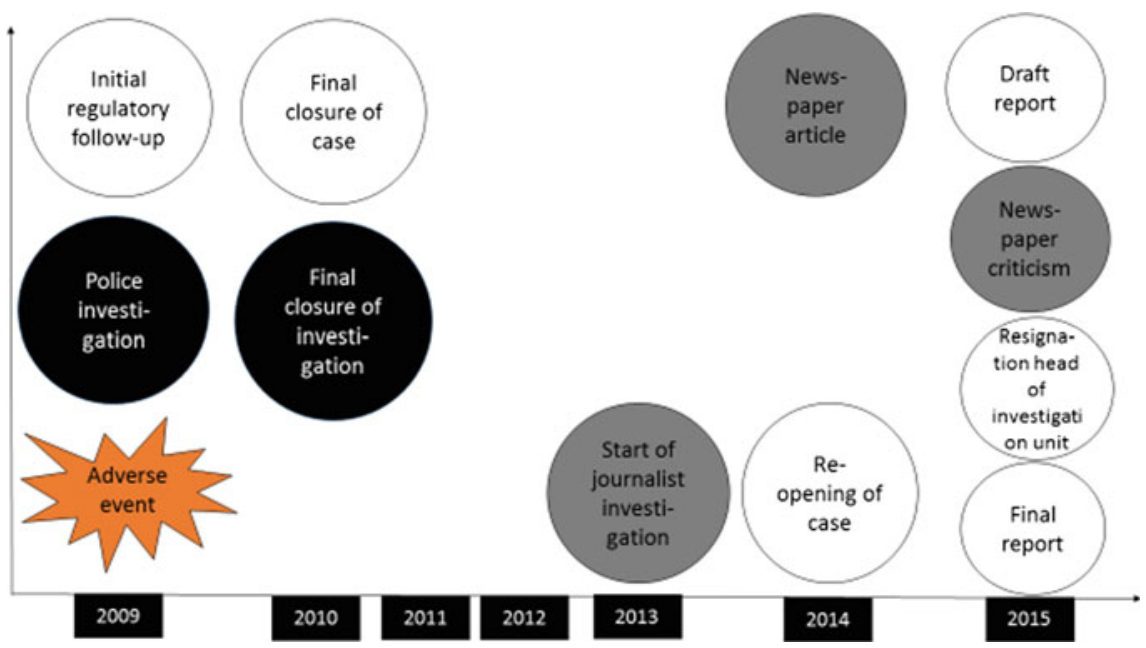

Fig. 1 Timeline of the Daniel case 
of blood for potential transfusion was ordered. After 3 hours, the patient was transferred to the general ward and observed in a four-bed room close to the nurses' guardroom. The patient's mother was concerned and uncomfortable with the nurses' lack of observational behaviour. At approximately 3:30 a.m., the patient's father became alarmed when the patient vomited blood. The nurse called the operating theatre team. According to the patient's father, they entered the operating room $20 \mathrm{~min}$ after he alarmed the nurses at 3:50 a.m. According to the nurse anaesthetist, the patient was in shock, but according to the surgeon the patient was still awake. The patient was unsuccessfully intubated with a tube without cuff guided by laryngoscope in general anaesthesia as blood hindered visualization of the deep part of the throat. The second intubation attempt was successful in terms of correct tube placement. A few seconds later the patient had cardiorespiratory collapse and cardiorespiratory resuscitation was started. During ongoing resuscitation, a bleeding spot was secured with compression and diathermia. The senior consultant surgeon, who arrived at the operating theatre at 4:12 a.m., heard a strange sound and suspected a tube dislocation that was corrected. Several attempts of venous access restoration were unsuccessful so fluid transfusion was not possible. The ATLS-trained (Advanced Trauma Life Support) resident surgeon was then called to assist the resuscitation. He established intraosseous access in the left tibia and transfusion of fluid, medication and blood was immediately started. Two hours later the patient was transferred to the Regional University Hospital, St Olav Hospital in Trondheim, where he died 4 days later. Autopsy showed massive brain oedema. Death was caused by severe hypoxemia due to bleeding shock with cardiac arrest (Helsetilsynet 2015a, b).

\section{Internal Follow-up Immediately After the Adverse Event}

Several critical issues for the case development were raised shortly after the adverse event. The hospital management did not carry out any formal debriefing. After Daniel's transfer, the involved healthcare professionals at Molde Hospital gathered, and the otorhinolaryngeal surgeon requested data from the anaesthesia monitoring equipment. However, this was impossible, as the data had already been deleted. The reason for this is not clear, but the nurse anaesthetist could not rule out that she had pressed 'the finish patient button', deleting all patient data. On February 2, the deputy managing director of the hospital called a joint meeting for all anaesthesia and otorhinolaryngeal doctors. There were major discrepancies in the narratives of the adverse event between the two professional groups. The chief otorhinolaryngeal doctor, who had not been present during the adverse event, argued that the meeting should not be held, partly due to old professional conflicts, and partly because of the upcoming police investigation. The otorhinolaryngeal perspective was negative, and they did not have an open and constructive discussion about the treatment of the patient. The meeting became a discussion of the reason for the patient's cardiorespiratory collapse. The anaesthetists suggested a loss of blood. The resident 
otorhinolaryngeal surgeon and the chief otorhinolaryngeal doctor were not given the opportunity to counter this suggestion. In addition, memories from a similar meeting in 2006 involving personal attacks on the otorhinolaryngeal staff revived old conflicts and the atmosphere was experienced as tense. According to the investigative report (Helsetilsynet 2015b), the anaesthetists claimed that the meeting as being normal. No minutes were written.

A few days later, the anaesthesia consultant visited the resident otorhinolaryngeal surgeon and asked him to reconsider the information he had included in the medical record. In addition, the resident explained that the anaesthesia consultant, who chaired the library meeting, had said, 'Remember that everybody did a good job', just before the resident went into the police interrogation. The resident felt threatened and pressured to revise information (Aftenposten, June, 5, 2015; Helsetilsynet 2015b). Shortly after this episode, the chief otorhinolaryngist explained that the chief anaesthesia doctor had come to his office. They had a rough discussion on causality, the rumours spreading through the hospital and challenges of developing common procedures between the otorhinolaryngeal and anaesthesia units. The discussion degenerated into a scolding, according to the chief otorhinolaryngist (Helsetilsynet 2015b). The investigative report does not present data on the chief anaesthetist's perception of this situation.

\section{Process of Police Investigation and Regulatory Follow-up in 2009}

In 2009, a regulatory follow-up and a police investigation were initiated. Both closed the case and concluded that there was no reason for regulatory sanctions or prosecution. The Regional Board of Health Supervision in the county and the police received reports from the hospital on an unnatural death, as required by law. Almost 6 months later, the Regional Board of Health Supervision requested the National Board of Health Supervision (NBHS) to assess prosecution. The NBHS did not find sufficient grounds for prosecution under the Health Professional Act, and the decision was upheld after a review of the documents from the police investigation (Helsetilsynet 2015b). The police had interrogated the healthcare professionals involved and consulted an expert in children's diseases. Based on the expert's opinion, and because the NBHS did not find sufficient evidence to prosecute, the police dismissed the case, concluding that there was no evidence of a crime. The expert on children's diseases concluded that even though mistakes had been made, no individuals were to blame. The hospital did not follow up the expert report with a learning perspective strategy and plan (Aftenposten, June, 22, 2014). 


\section{Media Push Causing a Reopening of the Regulatory Case in 2014}

The Daniel case was subject to regular media coverage in local and national news press and TV. A turning point came in June 2014 when media released new and highly relevant information:

In the documents that Aftenposten [newspaper] has access to, severe allegations are put forward indicating that hospital employees coordinated their depositions to the police. There moreover appear allegations on pressure and intimidation of healthcare professionals who refused to conform. Several at the hospital feared the results of the police investigation. (Aftenposten, June, 20, 2014)

Moreover, the parents expressed a need to clarify several unanswered questions, and the media information described a culture of fear, cover-ups, and claimed that healthcare professionals involved in Daniel's surgery had given incorrect information about his care. Based on the new media information in June 2014, the NBHS investigation group reopened the case and conducted an in-depth regulatory investigation to assess if the healthcare services provided in January 2009 had been done according to legal requirement of sound professional practice (a legal standard involving both institutions and individual healthcare professionals) (Helsetilsynet $2015 \mathrm{~b}$ ). The targets of the investigation included duties of documentation, internal follow-up of the event and whether the information and follow-up with the next of kin complied with the law.

\section{A New Transparency Strategy-Publishing a Preliminary Regulatory Investigation Report in 2015}

In June 2015, the NBHS chose a new transparency strategy, by publishing the draft version of the investigation report. The published draft concluded that the health care had been provided according to sound professional practice, but the internal follow-up and the hospital's error management and learning system had not met regulatory standards. The draft report, however, did not go into detail about the culture of fear, and the negative psychosocial work environment. The Daniel case was a high-profile case, and the conclusion created extensive media interest. The analysis, methods and perspectives applied by the regulator were heavily criticized by the public for leaving out the key subject of a negative psychosocial work environment (Aftenposten, July, 6, 2015; June, 19, 2015). The NBHS countered by saying that the work environment was outside of its mandate (Aftenposten, June, 19, 2015). 


\section{Taking Public Input into Account—Major Revision of the 2015 Final Report}

In November 2015, the NBHS published its final report. The NBHS explicitly stated that by publishing the draft report, it wanted to promote openness and obtain input on the draft report to shed new light on the case. As was customary in similar investigations, the health trust (providing specialist healthcare services, teaching and research), involved health professionals, and the next of kin can give feedback on the draft report. In this case, the media and several actors were able to provide new input on the draft. The NBHS also invited different stakeholders (Daniel's parents and grandparents, experts on clinical leadership, anaesthesia and law, patient ombudsman, patient association) to meetings to elaborate or clarify their input:

We have invited several of those who provided input [to the draft report] to meet us and elaborate their points of view, to ensure we have a correct understanding of their view. (Helsetilsynet 2015b: 14)

The NBHS changed its conclusion about the effects of the negative psychosocial work environment on patient safety. In the final report, several amendments appear. One key amendment is how the NBHS elaborates on the management's responsibility for ensuring a sound psychosocial working environment, as a prerequisite for patient safety. The establishment of this link between managerial responsibility, working environment and patient safety appears to be required if working environment issues are to be incorporated under the NBHS jurisdiction. The report, moreover, states that the supervisory follow-up of issues in the working environment falls under the jurisdiction of the Labour Inspection Authority, but when the working environment affects patient safety and the public trust in healthcare services, it will require an interface with the NBHS's supervision (Helsetilsynet $2015 \mathrm{~b}$ ). In the conclusion of the final report, the conclusion regarding sound professional practice, documentation requirements and follow-up with the next of kin remained the same, but the NBHS added a new paragraph on the psychosocial working environment:

\footnotetext{
After publishing the draft report, we have received new information indicating that there are still challenges related to working environment, which is of relevance for patient safety. We will therefore ask the County Governor [regional regulatory body] to follow up this issue as a specific case $[n e w] . .$. The further supervisory activity on how the health trust ensures the psychosocial working environment will be in collaboration with the Labour Inspection Authority. (Helsetilsynet 2015b: 79)
}

An additional amendment addresses the suggestions for future safety recommendation for learning purposes. Most of the recommendations pertain to the revision or establishment of procedures related to tonsillectomy on children; storage of data in anaesthesia monitoring equipment and surveillance units; information to and taking care of next of kin after severe adverse events; and handling of professional conflicts and personal clash of interest to prevent them from developing into conflicts that may threaten patient safety. The NBHS, moreover, suggests 
considering the establishment of new national guidelines for tonsillectomy, including an assessment of which hospitals should offer this surgery, their competence needs and guidelines for observation of post-operative haemorrhage. At last, the future recommendations state that NBHS will initiate dialogue with the Labour Inspection Authority regarding the overlapping jurisdiction concerning the psychosocial working environment in relation to sound patient treatment.

\section{Details on the Role of Media and Public Critique}

The final report provided amendments related to the media coverage of the Daniel case. In the draft report (Helsetilsynet 2015a), the role of media is described in one short paragraph. The comparison between the draft (Helsetilsynet 2015a) and final report (Helsetilsynet 2015b) illustrates much greater attention to the details of the media's role. In particular, we find more information on how the Aftenposten journalist worked on the case. The journalist claimed that in 2013, an employee who was not involved in the case tipped him off about 'war-conditions' between doctors at Molde Hospital, after a child's death following a routine operation in 2009. The journalist met with the child's parents and relatives, who described a situation of total repudiation of liability. He also obtained a disc containing all files in the case. The investigative report does not say anything about how the journalist got access to the disc, but he presented it to a lawyer and two doctors. Based on their feedback on the content, the journalist focused his attention on accusations of collusion and pressures and on why the regulatory authorities had closed the case in 2009 (Helsetilsynet 2015b).

After publication of the draft report, one of the experts that Aftenposten asked to comment on the case (co-author Olav Røise) argued that NBHS did not go into details on several issues in the report, including the accusations of pressure to adapt their version of the story to the police. Possible reasons for this could be a lack of competence or clinical experience among the investigatory team members, as he explained in the newspaper interview (Aftenposten, July, 6, 2015). Shortly after this critique, the head of the investigatory unit in NBHS called the expert. In a letter to the director of NBHS, the expert explained how the head of the investigative unit had approached him (Aftenposten, Sept. 3, 2015):

In the letter [Expert] writes that [head of investigation unit] told him that it could "harm him" if he presented the critique in public. She pointed out that this would harm doctors at Molde Hospital as well. According to the letter, [Head of investigative unit] also said, that [expert] had made "horrific accusations" about her unit, not holding the correct competence to assess if Daniel had received sound professional treatment at Molde Hospital.

Shortly thereafter, the head of investigatory unit resigned (Aftenposten, Sept. 3, 2015). The media's role in the Daniel case has been acknowledged both by Daniel's parents and the NBHS. Both the parents and the NBHS argue that the case would not have been reopened, and the conclusions would not have been revised, without newspaper attention (Aftenposten, Nov. 19, 2015). 


\section{Discussion}

\section{Tonsil Surgery-What Do We Know About the Risk from a Medical Perspective?}

Tonsil surgery, with or without adenoidectomy, is technically a simple procedure learned at the early stages of surgical training. It is among the most common surgical procedures in the world. However, the procedure is associated with potential severe and lethal complications that are very rare and therefore not considered an important risk factor when operation is offered to the patient or to a child's parents. In a Swedish study based on data from the National Patient Register (NPR) matched with the National Cause of Death Register over an 8-year period (2004-2011), the incidence for lethal outcome after benign tonsil surgery was 1 out of 41,263 operations (Ostvoll et al. 2015). This means that an operation with lethal outcome, based on the Swedish data, will be seen about once every 8 years in Norway, providing that the indications for surgery are the same.

In Austria in 2006 and 2007, five children under the age of six died after tonsillectomy (Sarny et al. 2013). This led to a public and emotional discussion on risk after tonsil surgery resulting in a consensus paper with the goal of making the procedure safer. The indication for doing tonsillectomy was restricted and tonsillotomy - a less invasive procedure-was advocated for children younger than 6 years of age. This consensus strategy was followed up with-to our knowledgethe only large-scale register study including all tonsil surgeries in Austria for 9 months in 2009-2010 disclosing safety data (Sarny et al. 2013). In their series, a haemorrhage rate of $12.3 \%$ for tonsillectomy and $2.3 \%$ for tonsillotomy was reported. Four percent of the patients with haemorrhage after tonsillectomies needed secondary surgery. Almost none in the tonsillotomy group needed secondary operation. The study also showed that repeated episodes of minor post-operative bleeding were a warning sign for further bleeding. According to the authors, the Austrian experience brought changes in education prior to surgery. Patients were given detailed information about what to watch for after a child's operation and what to do in case of haemorrhage.

\section{Media as Whistleblower in Risk Communication}

By exploring the Daniel case, we have seen how a tonsillectomy case characterized by cover-up, failure of the initial regulatory and hospital follow-up, came to a head when media shone a spotlight on the case (Hinchcliff et al. 2012; Mannion and Davies 2015; Millenson 2002; Waring 2015). By bringing new information to the table including critique of regulatory follow-up, the regulatory body appeared left with no other option than to re-open the case. They then continued with a strategy of transparency (Bouder et al. 2015), uncommon in a Norwegian setting, releasing 
draft report to the public, inviting experts to provide input, reflecting upon the media role and by making new safety recommendations to a wide range of actors.

The role of journalism in patient safety is interesting (Hinschcliff et al. 2012; Millenson 2002), and our study is reminiscent of findings from the early days of the patient safety movement. Millenson (2002) argued that until journalists took an interest in patient safety, it had not received much attention. As our study showed, this has similarities with the Daniel case where the regulator and the police closed the case, despite having collected information on possible cover-ups and professional battles after the event. News media gave the Daniel case renewed urgency. Moreover, the 'people-like-you' perspective in Millenson's (2002) study, is part of the Daniel case, where people like the readers or their children could die from a routine tonsil surgery. This framing places a human face on the formal parties involved (hospital, healthcare professionals and regulators).

\section{Amplification of Events and Transparency}

The regulator applied a new strategy of transparency in the Daniel case. The Social Amplification of Risk Framework (Pidgeon et al. 2003) claims that the social and economic impacts of an adverse event like Daniel's death are determined not only by the direct physical consequences of the event but also by the interaction of psychological, cultural, social and institutional processes amplifying or attenuating public experience of the event, resulting in secondary impacts (Pidgeon et al. 2003; Renn et al. 1992). By publishing new information and consulting powerful experts, we contend that the news media started an amplification process with consequences of loss of credibility in the initial regulatory follow-up, causing the case to be reopened and the findings in the final report substantially changed. This new transparency can be interpreted as a way of reconstructing the credibility of the regulatory investigation (Lofsted 2010) by making the process as open and transparent as possible in terms of information sources, regulatory assessments and rationality, use of input from journalists, experts, healthcare professionals and next of kin. In the transparency literature (Bouder, et al. 2015; Coglianese 2009), this approach is termed a reasoned form of transparency.

This is different from fish-bowl transparency: full disclosure without explanatory information or contextualization. Reasoned transparency accepts that transparency, as information disclosure alone, is not a solution. Reasoned transparency policies demand that regulators or government officials 'offer explicit explanations for their actions', the facts and evidence they base decisions on (Bouder et al. 2015; Coglianese 2009). In our case, we revealed several links to the reasoning approach, for example when and why the NBHS initially excluded psychosocial working environment from the draft report, and then argued why it had been added to the conclusion of the final report. The media coverage and reasoned transparency approach had societal impacts (Pidgeon et al. 2003). The safety recommendations manifest some of the societal impacts by suggesting new procedures, guidelines and 
clearer interface between regulatory authorities (Board of Health and Labor Inspectorate) and the coordination of inspection activities.

Transparency related to the adverse event is high on the agenda in Norwegian health care and elsewhere (Blomgren 2007; Kurtzman and Jennings 2008; Tavare 2012). The development can be interpreted as part of a risk communication strategy focusing on openness to patients and the public (Bouder et al. 2015; Kasperson et al. 1988; Lofstedt et al. 2011). Under the Social Amplification of Risk Framework (Pidgeon et al. 2003), the increased demand for transparency is not necessarily welcomed by healthcare professionals or regulators. These actors may fear the role of media and wish to go under the radar to avoid negative publicity and reputation risk, following media's role in risk communication and amplification processes. We saw this in the Daniel case when healthcare professionals were pressured to align their explanations, and when the director of the investigation unit at NBHS called one of the experts, and warned him that public criticism in the media would damage him and other doctors at the hospital. We can interpret these reactions, as an attempt to reduce the expected amplifications and ripple effects (Pidgeon et al. 2003) caused by fleshing out the event and critics in the media.

\section{Conclusion}

Transparency is not a panacea and involves trade-offs. More democracy, more freedom of information and more efficiency are expected from transparency, but may cause a society of control, with few confidential spaces (Han 2015), and escalating costs to meet performance demands (Hood and Dixon 2015). Healthcare innovations, regulation and safety improvement processes involve conflicts, professional discussions, mistakes and new ideas. Healthcare professionals and regulators need confidential space for debate and disagreement (Becker 1999). This is not the same as a cover-up or collusion to conceal an adverse event from the public. By using the Daniel case as emblematic of Norwegian risk communication strategies in health care, improvements should be made along the lines of direct and adequate information exchange according to patient rights, and efforts to foster open and transparent regulatory and organizational cultures to ensure public trust.

Declaration of interest Co-author, Olav Røise, was involved in the media coverage of the Daniel case as a clinical expert who was asked to give an assessment of the draft report described in the results section: Details on the role of media and public critique.

\section{References}

Aase, K., \& Rosness, R. (2015). Organisatoriske ulykker og resiliente organisasjoner i helsetjenesten - ulike perspektiver. In: Aase, K. (Ed.), Pasientsikkerhet - teori og praksis, (pp. 25-47). Oslo: Universitetsforlaget. (Title: Patient Safety—Theory and Practice). 
AHUS. (2015). AHUS web page on patient safety including 3-3 reports and quality indicators. http://www.ahus.no/fagfolk_/temasider_/Sider/pasientsikkerhet.aspx.

Becker, G. (1999). From theory to practice - On the difficulties of improving human-factors learning from adverse events in an inhospitable environment. In Misumi, J., Wilpert, B., Miller, R. (eds) (1999). Nuclear Safety - A human factors perspective. London: Taylor \& Francis.

Blomgren, M. (2007). The drive for transparency: Organizational field transformation in Swedish healthcare. Public Administration, 85(1), 67-82.

Bouder, F., Way, D., Löfstedt, R., \& Evensen, D. (2015). Transparency in Europe: A quantitative study. Risk Analysis, 35(7), 1210-1229.

Braithwaite, J, Wears, R. L., \& Hollnagel, E. (2015). Resilient health care: Turning patient safety on its head. International Journal for Quality in Health Care, 1-3. https://doi.org/10.1093/ intqhe/mzv063.

Coglianese, C. (2009). The transparency president? The Obama administration and open government. Governance, 22(4), 529-544.

Francis, R. (2013). Report of the mid staffordshire NHS foundation trust public inquiry executive summary. London: The Stationery Office.

Francis, R. (2015). Freedom to speak up. London: TSO. http://webarchive.nationalarchives.gov. uk/20150218150343/, https://freedomtospeakup.org.uk/wp-content/uploads/2014/07/F2SU_ Executive-summary.pdf.

Han, B.-C. (2015). The transparency society. Stanford: Stanford University Press.

Hannawa, A. F., Shigemoto, Y., \& Little, T. D. (2016). Medical errors: Disclosure styles, interpersonal forgiveness, and outcomes. Social Science and Medicine, 156, 29-38. https://doi. org/10.1016/j.socscimed.2016.03.026.

Helsetilsynet. (2015a). Utkast til rapport i tilsynssak—dødsfall etter postoperative komplikasjoner etter tonsillektomi. (Draft investigation report).

Helsetilsynet. (2015b). Tilsynsrapport etter alvorlig hendelse (Danielsaken). (Final investigation report).

Hinchcliff, R., Westbrook, J., Greenfield, D., Baysari, M., Moldovan, M., \& Braithwaite, J. (2012). Analysis of Australian newspaper coverage of medication errors. International Journal for Quality in Health Care, 24(1), 1-8.

Hood, C., \& Dixon, R. (2015). A government that worked better and cost less? Evaluating three decades of reform and change in the UK central government. Oxford: Oxford University Press.

Johnstone, J., \& Kanitsaki, O. (2006). The ethics and practical importance of defining, distinguishing and disclosing nursing errors: A discussion paper. International Journal of Nursing Studies, 43(3), 367-376.

Kasperson, R. E., Renn, O., Slovic, P., Brown, H. S., EMel, R., Goble, J.X. et al. (1988). The social amplification of risk: A conceptual framework. Risk Analysis, 8, 177-187.

Kurtzman, E. T., \& Jennings, B. M. (2008). Trends in transparency. The Journal of Nursing Administration, 38(7/8), 349-354.

Liang B. A., \& Lovett K. M. (2013). Error disclosure. In Agrawal, A. (Ed.), Patient safety-A case-based comprehensive guide (pp. 329-340). New York: Springer Science and Business Media New York.

Lofsted, R. (2010). Risk communication guidelines for Europe: A modest proposition. Journal of Risk Research, 13(1), 87-109.

Lofstedt, R., Bouder, F., Wardman, J., \& Chakraborty, S. (2011). The changing nature of communication and regulation of risk in Europe. Journal of Risk Research, 14(4), 409-429.

Mannion, R., \& Davies, H. T. O. (2015). Cultures of silence and cultures of voice: The role of whistleblowing in healthcare organizations. International Journal of Health Policy Management, 4(8), 503-505.

Millenson, M. L. (2002). Pushing the profession: how the news media turned patient safety into a priority. Quality and Safety in Health Care, 11, 57-63. 
NOU. (2015:11). "Med åpne kort - forebygging og oppfølgning av alvorlige hendelser $i$ helse - og omsorgstjenesten". Departementenes sikkerhets- og serviceorganisasjon Informasjonsforvaltning.

O'Connor, R. E. (2016). Transparency and the regulatory process in Europe and the United States: Two research priorities. Journal of Risk Research, 19(9), 1129-1140. https://doi.org/10.1080/ 13669877.2015.1071866.

Ostvoll, E., Sunnergren, O., Ericsson, E., Hemlin, C., Hultcrantz, E., Odhagen, E., et al. (2015). Mortality after tonsil surgery, a population study, covering eight years and 82,527 operations in Sweden. European Archives of OTO-Rhino-Laryngology: Official Journal of the European Federation of OTO-Rhino-Laryngological Societies, 272(3), 737-743.

OUS. (2015). Oslo University Hospital's web page on patient safety. http://www. oslouniversitetssykehus.no/fagfolk_/kvalitet_/pasientsikkerhet_/Sider/side.aspx.

Pidgeon, N., Kasperson, R. E., \& Slovic, P. (Eds.). (2003). The social amplification of risk. Cambridge, Mass: Cambridge University Press.

Pope, C., Ziebland, S., \& Mays, N. (2006). Analysing qualitative data. In C. Pope \& N. Mays (Eds.), Qualitative research in health care (pp. 63-82). Oxford: BMJ Books.

Renn, O., Burns, W. J., Kasperson, J. X., Kasperson, R. E., \& Slovic, P. (1992). The social amplification of risk: Theoretical foundations and empirical applications. Journal of Social Issues, 48(4), 137-160.

Sarny, S., Habermann, W., Ossimitz, G., \& Stammberger, H. (2013). What lessons can be learned from the Austrian events? ORL; Journal for OTO-Rhino-Laryngology and Its Related Specialties, 75(3), 175-181. PubMed PMID: 23978805.

Stake, R. E. (1994). Case studies. In N. K. Denzin \& Y. S. Lincoln (Eds.), Handbook of qualitative research (pp. 236-247). Thousand Oaks: Sage Publications.

Tavare, A. (2012). Where are we with transparency over performance of doctors and institutions? BMJ, 345, e4464.

Waring, J. (2015). When whistle-blowers become the story: The problem of the third victim. International Journal of Health Policy and Management, 5(2), 133-135.

Wiig, S., \& Lindøe, P. H. (2009). Patient safety in the interface between hospital and risk regulator. Journal of Risk Research, 12(3-4), 411-427.

Woodier, N. (2015). Moving from Safety I to Safety II, but what about the media? BMJ Quality \& Safety, 24, 178. https://doi.org/10.1136/bmjqs-2014-003827.

Open Access This chapter is licensed under the terms of the Creative Commons Attribution 4.0 International License (http://creativecommons.org/licenses/by/4.0/), which permits use, sharing, adaptation, distribution and reproduction in any medium or format, as long as you give appropriate credit to the original author(s) and the source, provide a link to the Creative Commons license and indicate if changes were made.

The images or other third party material in this chapter are included in the chapter's Creative Commons license, unless indicated otherwise in a credit line to the material. If material is not included in the chapter's Creative Commons license and your intended use is not permitted by statutory regulation or exceeds the permitted use, you will need to obtain permission directly from the copyright holder.

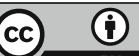

